\title{
PARENTALIDADE ADOTIVA: UM ESTUDO DE CASO LONGITUDINAL COM FAMÍLIAS HOMOAFETIVAS E HETEROAFETIVAS*
}

ADOPTIVE PARENTING: A LONGITUDINAL CASE STUDY WITH HOMO-AFFECTIVE AND HETERO-AFFECTIVE FAMILIES

\section{ELISA AVELLAR MERÇON-VARGAS 1, REBECA VALADÃO BUSSINGER 2, EDINETE MARIA ROSA 3}

1., 3. UNIVERSIDADE FEDERAL DO ESPÍRITO SANTO (UFES), Vitória, Espírito Santo, Brasil

2. UNIVERSIDADE FEDERAL DO SUL DA BAHIA (UFSB), Texeira de Freitas, Bahia, Brasil

\begin{abstract}
INTRODUCTION: Homoparenthood has been the focus of recent studies, evidencing the importance to understand the dynamics of these families compared to hetero-parental ones. OBJECTIVES: Thus, this study sought to understand the beliefs and parental practices of a hetero-affective adoptive family and a homoaffective family with young children (up to three years old). METHOD: Seven interviews were conducted with parents at two-point times with an approximate interval of one year and eight months. For data analysis we used content analysis. RESULTS: The results showed parenting practices based on dialogue in the homoaffective family and obedience in the hetero-affective family, as well as different ways of dealing with gender issues. CONCLUSIONS: We emphasize that it is the beliefs reflected in daily practices that promote healthy psychological development and growth.
\end{abstract}

KEY WORDS: Adoption, Adoptive families, Homoaffective families, Parenting.

CÓMO CITAR / HOW TO CITE

Merçon-Vargas, E. A., Valadão Bussinger, R., \& Maria Rosa, E. (2020). Parentalidade adotiva: Um estudo de caso longitudinal com famílias homoafetivas e heteroafetivas. Salud \& Sociedad, 11, e3833. doi: 10.22199/issn.0718-7475-2020-0002

\footnotetext{
* Financiamiento: Fundação de Ampar o à Pesquisa e Inovação do Espírito Santo (FAPES) [\#0699/2015] e Programa Nacional de Pós-Doutorado da Coordenação de Pessoal de Nível Superior (PNPD/CAPES) [\#88882.315866/2019-01].

1. E-mail: elisa.amv@gmail.com•ORCID: https://orcid.org/0000-0003-1229-3122; 2. E-mail: rebecabussinger@hotmail.com•0RCID: https://orcid.org/0000-0002-8244-3598 3. E-mail: edineter@gmail.com・0RCID: https://orcid.org/0000-0003-4279-8308
} 
Dentre as temáticas que se encaixam no âmbito de proteção aos direitos da criança está a adoção. Inspiradas na doutrina da proteção integral e no melhor interesse da criança, um conjunto de legislações no Brasil demarca as diretrizes legais para adoção. De acordo com o Estatuto da Criança e do Adolescente (ECRIAD), a convivência familiar é um direito da criança e do adolescente. Quando não é possível essa convivência na família de origem, a garantia desse direito deve se dar através da inserção da criança em uma família substituta por meio de guarda, tutela ou adoção. A adoção caracteriza-se por um recurso legal irrevogável que se dá em casos excepcionais e que proporciona à criança ou ao adolescente a inserção em uma nova família. A filiação por meio da adoção garante aos filhos os mesmos direitos e deveres dos filhos biológicos (Lei n. 8.069, 1990).

A prática da adoção tem sido estudada nos campos das ciências sociais, jurídicas e psicológicas, buscando a compreensão dos diferentes aspectos que permeiam 0 cotidiano de quem a vivência (Palacios \& Brodzynsky, 2010). Dentre os aspectos que tem recentemente chamado a atenção de pesquisadores está a constituição familiar por casais homoafetivos (Merçon-Vargas, Rosa, \& Dell'Aglio, 2015; Tombolato, Maia, \& Santos, 2019). Alguns pesquisadores apontam para o estigma e preconceito que perpassam as adoções por casais homoafetivos (Araldi \& Serralta, 2019; Araújo, Oliveira, Sousa, \& Castanha, 2007; Cecílio, Scorsolini-Comin, \& Santos, 2013; Farr, 2017; Goldberg \& Smith, 2011; Pereira, Torres, Falcão, \& Pereira, 2013).

Por exemplo, Araújo et al. (2007) encontraram que a maioria dos alunos de graduação de direito e psicologia se posicionaram contrariamente à adoção por esses casais. Segundo os autores, esse posicionamento poderia ser atribuído às crenças de que a criança seguirá a mesma orientação sexual dos pais adotivos, não terá uma referência masculina ou feminina, e a preocupação de que a criança será alvo de preconceito. Também nos Estados Unidos, Farr (2017) indicou que a adoção de crianças por casais homoafetivos divide opiniões públicas; de forma semelhante ao Brasil, esta controvérsia está centrada na discussão de se a criança precisa de uma figura materna e outra paterna para o seu desenvolvimento saudável, dentre outras questões. $O$ estigma social e a discriminação podem afetar o funcionamento familiar, bem como o desenvolvimento da criança em famílias homoparentais. No entanto, se por um lado a experiência de discriminação está ligada a estigmatização da sexualidade, uso abusivo da mídia, e problemas de saúde mental (dentre outros), por outro lado o apoio social pode amenizar esses efeitos (Araldi \& Serralta, 2019; Farr, 2017; Goldberg \& Smith, 2011).

Dessa forma, algumas das particularidades vivenciadas na adoção por casais homoafetivos, em comparação aos heteroafetivos diz respeito ao enfrentamento do preconceito relacionado a orientação sexual dos pais (Araldi \& Serralta, 2019; Tombolato et al., 2019). Apesar disso, as modificações no cenário da adoção bem como 0 reconhecimento do casamento homoafetivo têm proporcionado maior visibilidade a adoção por essas famílias, ainda que preteridos frente às famílias heteroafetivas (Coitinho Filho, 2017). Assim, ainda que a sociedade contemporânea tenha apresentado transformações com relação aos modelos de família, parece que o modelo tradicional e heteronormativo permanece como referência (Ruiz, Borges, Hueb, Tilio, \& Scorsolini-Comin, 2019).

Com relação as questões de vivências e práticas parentais, Cecílio et al. (2013) apontaram que há indícios de que famílias homoafetivas seriam mais flexíveis em seus papéis. Isso também foi indicado pelos resultados das teses de doutorado de Farias (2017) e Temperini (2018) com famílias homoparentais e nos resultados encontrados por Araldi e Serralta (2019) e Rosa, Melo, 
Boris e Santos (2016). Alguns estudos internacionais também indicaram um funcionamento mais positivo em famílias homoafetivas em comparação às heteroafetivas. Por exemplo, o estudo de Golombok et al. (2014) com pais adotivos gays, lésbicas e heterossexuais indicou um maior bem-estar parental e práticas parentais mais positivas (e.g., mais interações, maior responsividade, menos agressão, etc.) em famílias com pais gays comparadas às heteroafetivas. Ainda, os problemas de comportamentos externalizantes foram maiores entre crianças em famílias adotivas heteroafetivas. Farr e Patterson (2013) também encontraram que pais em familias homoafetivas nos Estados Unidos participavam mais durante interações familiares do que pais heterossexuais. Além disso, enquanto os casais homoafetivos compartilhavam o cuidado da criança, os heteroafetivos relataram que as mães eram quem cuidavam mais das crianças (seguindo um modelo tradicional). No Brasil, o estudo de mestrado de Reppold (2001), visando investigar as associações entre autoestima, depressão, estilo parental e adoção, encontrou que a responsividade parental apresentou os maiores efeitos sobre a saúde emocional dos filhos.

Esses autores sugerem que são as variáveis de processo familiar-como menor estresse parental, coparentalidade e 0 suporte mútuo-que estariam associadas ao desenvolvimento saudável das crianças, e não a orientação sexual dos pais em si (Farr, 2017; Farr \& Patterson, 2013; Golombok et al., 2014; Reppold, 2001). De forma semelhante, em um estudo longitudinal, Farr (2017) encontrou que os problemas comportamentais das crianças em famílias adotivas estavam relacionados ao estresse parental e não a orientação sexual dos pais, chamando atenção para a importância de como se dão as relações familiares. Segundo Reppold (2001), as estratégias de socialização parental servem como moderadoras do desenvolvimento dos filhos. Isso está de acordo com as ideias supracitadas de que as interações e atividades diárias são os principais promotores do desenvolvimento saudável, para além da estrutura familiar.

Há que se considerar ainda que a parentalidade e as atividades diárias são informadas pelas etnoteorias, que são sistemas de crenças sobre a criação dos filhos e os objetivos de socialização neles incorporados (ver por exemplo, Harkness et al., 2010; Kağıtçıbaşı, 2007; Keller, 2007; Tudge, 2008). A etnoteoria se reflete nas metas e práticas de socialização dos pais; diferentes práticas, por sua vez, resultarão em diferentes trajetórias de desenvolvimento (Harkness et al., 2010; Keller, 2007). Assim, ligadas ao exercício da parentalidade estão as crenças e metas de socialização que indicam as características desejáveis na criança no futuro e podem refletir valores amplos presentes em um determinado grupo social. Por exemplo, Seidl-de-Moura et al. (2008) encontraram que mães brasileiras possuíam como metas de socialização para seus filhos pequenos principalmente o bom comportamento e a autonomia, apesar dessas metas serem influenciadas por diversos fatores, como o nível educacional das mães.

Nas últimas décadas houve avanços expressivos no conhecimento sobre famílias adotivas com diferentes composições, incluindo famílias adotivas homoparentais brasileiras, demonstrando a importância de se compreender a diversidade familiar. Como apontado por Ruiz et al. (2019), é importante compreender como casais em famílias adotivas com configurações diferentes exercem seus papéis parentais para que se possa compreender as novas configurações familiares, bem como minimizar as consequências das possíveis discriminações vivenciadas por algumas dessas famílias.

Os estudos de Farias (2017) e Temperini (2018) também evidenciaram a importância de se considerar a vivência de preconceitos 
com a relação a orientação sexual dos pais em famílias homoafetivas; Farias, por exemplo, discutiu 0 preconceito experienciado por essas famílias em diversos âmbitos (e.g., ao lidar com planos de saúde, vizinhos, profissionais da saúde, etc.). Já Temperini aponta para a percepção de que famílias homoparentais teriam baixa aceitação social, tanto nos Estados Unidos como no Brasil. Com base nisso, o presente estudo buscou compreender longitudinalmente os contextos de adoção, as crenças e práticas parentais em geral e relacionadas especificamente a como os pais lidavam e ensinavam seus filhos (direta e indiretamente) sobre adoção e gênero em uma família adotiva heteroafetiva e outra homoafetiva.

\section{MÉTODO}

Trata-se de um estudo qualitativo e longitudinal, no qual as famílias foram acompanhadas por cerca de um ano e oito meses, com entrevistas realizadas a cada seis meses aproximadamente. $O$ desenho da pesquisa foi pensado como longitudinal desde 0 início, com os intervalos de tempo entre as coletas predeterminados (Hemanowicz, 2016), apesar de ter havido flexibilidade nos intervalos de acordo com a disponibilidade dos participantes. Segundo Hermanowicz (2016), a compreensão de um fenômeno longitudinalmente põe em primeiro plano a ideia de trajetória, focando atenção no curso das experiências de vida e eventos.

\section{Participantes}

Este estudo faz parte de um projeto maior que acompanhou sete famílias adotivas ao longo do tempo. Para o presente estudo, duas famílias foram selecionadas de acordo com a orientação sexual dos casais (uma homoafetiva e outra heteroafetiva). Outros critérios de inclusão foram a idade dos filhos por adoção no momento da primeira entrevista (ambas famílias possuíam filhos com até três anos de idade) e famílias em que os dois pais/mães haviam participado das coletas de dados no primeiro e no último momento da entrevista. Apesar das famílias selecionadas diferirem em relação ao nível de escolaridade, renda média e raça/cor (o que provavelmente está ligado aos valores, crenças e práticas das famílias), nosso foco foi na comparação de casais com diferentes orientações sexuais a fim de explorar potenciais semelhanças e diferenças na vivência dessas famílias. Assim, trata-se de um estudo de casos múltiplos (Yin, 2010) longitudinal que buscou compreender como os participantes sucessivamente atribuíam significados as suas trajetórias de vida ligadas à adoção.

\section{Instrumentos}

Foi utilizado um protocolo de entrevista semelhante em cada momento da coleta de dados, com adaptações feitas nos roteiros para os momentos posteriores ao primeiro encontro, de acordo com as demandas surgidas ao longo da pesquisa. Essas adaptações foram necessárias diante dos significados e a significância dos dados que foram emergindo na medida em que os pesquisadores formulavam interpretações dos fenômenos (Hermanowicz, 2016). Dessa forma, no primeiro momento, o roteiro de entrevista semiestruturado incluiu os seguintes tópicos: (a) dados sócio demográficos, (b) o processo de adoção, (c) rotina e adaptação familiar, (d) construção da parentalidade, e (e) outros contextos. No último momento de entrevistas foram adicionados os seguintes tópicos: (a) sentimentos relacionados à participação da pesquisa ao longo do tempo, (b) mudanças percebidas no cotidiano e relações familiares ao longo do tempo e (c) mudanças percebidas em si e na criança ao longo do tempo.

\section{Procedimento}

Para o presente trabalho, foram analisadas as entrevistas realizadas no primeiro e no último momento-ou seja, dados com um intervalo de um ano e oito meses-com intuito de apreender as mudanças ocorridas em um intervalo suficiente para gerar 
mudanças na dinâmica familiar. Foram realizadas um total de sete entrevistas, sendo que a primeira entrevista com o casal heterossexual ocorreu em conjunto. As entrevistas com a família heteroafetiva foram realizadas em novembro de 2016 e em julho de 2018 (intervalo de 1 ano e 8 meses), e as entrevistas com a familia homoafetiva foram realizadas em abril de 2017 e em janeiro de 2019 (intervalo de 1 ano e 9 meses).

Este estudo seguiu as diretrizes previstas na Resolução $n^{0}$ 510/2016 do Conselho Nacional de Saúde (2016), tendo sido obtido aprovação pelo Comitễ de Ética em Pesquisa da Universidade Federal do Espírito Santo previamente a coleta de dados (inscrições 56447616.3.0000.5542 \& 02886818.6.0000.5542). Os participantes concordaram com suas participações e assinaram o termo de consentimento livre e esclarecido em todos os momentos da pesquisa, após serem explicados sobre os riscos e benefícios, bem como seus direitos. Foi garantido o sigilo dos dados pessoais que pudessem identificar os participantes; para tanto, nomes fictícios foram utilizados nos resultados, com a família homoafetiva sendo identificada com nomes iniciados com A e a heteroafetiva com nomes iniciados com B.

\section{Análise}

Os dados obtidos foram analisados por meio da análise de conteúdo por permitir a análise crítica do conteúdo manifesto pelos entrevistados, além dos seus significados (Bardin, 2004); as categorias foram criadas a posteriori. As seguintes categorias de análise surgiram a partir das entrevistas: (a) 0 contexto da adoção, (b) as crenças e práticas parentais, (c) a socialização parental sobre adoção, e (d) a socialização parental sobre gênero. Para as análises longitudinais, foi utilizado o modo interativo que, de acordo com Hemanowicz (2016), enfatiza a representação e descreve os objetos de estudo a cada momento da coleta de dados em separado, mas longitudinalmente com foco em continuidades e mudanças (ao invés de transversalmente). As questões trazidas no primeiro momento e no último momento foram discutidas tanto de forma sincrônica (comparando as famílias em um mesmo momento de entrevista; ou seja, transversalmente) como diacrônica (observando mudanças e continuidades nos dois momentos de entrevistas aqui abordados; Hermanowicz, 2016).

\section{RESULTADOS}

\section{Caracterização das Famílias}

No momento da primeira entrevista, o casal Adriana (23 anos) e Aline (35 anos) não possuía filhos biológicos e havia adotado um menino (Arthur) aos 2 meses e meio de idade; Arthur tinha 1 ano e 4 meses no momento da primeira entrevista. A renda familiar era de cerca de 3 salários mínimos. Adriana havia completado o ensino médio e era dona de casa (tendo começado a trabalhar meio período no negócio da família no último momento de entrevista), enquanto Aline possuía ensino superior incompleto e trabalhava fora. Ambas se declararam brancas.

O casal Bianca (39 anos) e Bernardo (48 anos) também não possuía filhos biológicos e adotou duas crianças, uma menina (Bárbara) recém-nascida e um menino (Bruno) com 9 meses de idade; no momento da primeira entrevista, a menina tinha 3 anos e o menino 1 ano e 9 meses. A renda familiar era de cerca de 6 a 9 salários mínimos. Bianca havia completado o ensino técnico e trabalhava em uma empresa e Bernardo havia completado mestrado e atuava como professor no ensino médio. Ela se declarou parda e ele negro.

\section{O Contexto da Adoção}

A forma como se deu o processo de adoção em cada família é importante para a compreensão das dinâmicas familiares. Observamos algumas semelhanças e peculiaridades em cada caso acompanhado. No caso da família heteroafetiva, a adoção 
da primeira filha havia sido "à brasileira" (entregue pela mãe biológica diretamente à família adotiva) e legalizada posteriormente. Já a adoção do segundo filho ocorreu dentro dos trâmites legais desde 0 início, tendo 0 casal ficado na fila da adoção por cerca de dois anos, tempo semelhante ao esperado pela família homoafetiva (1 ano e 9 meses). Com relação à "adoção à brasileira," Bernardo afirmou:

Só esclarecendo que se a mãe dá pra gente ... foi um processo ... Como eu diria? Nós acompanhamos a gravidez da mãe da Bárbara, porque ficamos sabendo de uma senhora que já tinha vários filhos e não teria condições de ter mais um. A mulher estava grávida $e$ isto chegou ao nosso conhecimento, ao conhecimento da Bianca. E nós acompanhamos parte da gestação, né, levamos a pessoa na maternidade quando foi ganhar o neném e trouxemos a Bárbara pra casa. À posteriori, a gente entrou com o processo de adoção. A advogada até nos orientou que não fizéssemos mais isso, porque 0 caso dela foi um tanto arriscado, né. (Bernardo, pai)

Esta temática também foi trazida no último momento de entrevistas com o casal heteroafetivo. 0 casal comparou a adoção da filha mais velha com os procedimentos legais e burocráticos de uma adoção por vias legais, vividos na adoção do filho mais novo. Segundo a mãe,

Eu mudaria [o processo de adoção] no sentido da adoção à brasileira. Experiência minha mesmo com a Bárbara né, porque você sabe que a Bárbara, a mãe dela deu ela pra mim. Eu acho que essas famílias que não têm condição deveriam sentir ... se ela sentisse confiança de entregar essa criança pra uma pessoa que sabe que vai cuidar e vai amar, eu acho que ela deveria ter essa opção, né. Igual tem fora do Brasil. A mãe escolhe a familia que vai dar a criança mesmo estando na barriga, eu acho que deveria ter essa opção. (Bianca, mãe)

O desejo da adoção vinha de ambosBernardo e Bianca-que haviam começado a conversar sobre isso ainda no primeiro ano de namoro. Ademais, o casal afirmou que buscou a adoção de uma criança menor do que dois anos, pois não estavam convencidos de que crianças mais velhas poderiam se adaptar facilmente a família.

Já o casal homoafetivo descreveu que a princípio a iniciativa da adoção vinha apenas de Adriana, mas, com o tempo, ela convenceu a companheira a tornar-se mãe. Para elas, o casal que adota não faz o bem apenas para a criança, mas há uma reciprocidade nesse processo. De forma similar à família heteroafetiva, Adriana criticou a burocracia e morosidade que muitas vezes acontecem no processo de destituição do poder familiar de crianças que precisam de uma família. Segundo Adriana,

A partir do momento que um pai e uma mãe não quer, aí eles ainda tentam colocar aquela criança de novo no vínculo familiar, tentam fazer as vezes a criança passar de novo pelo trauma pra depois destituir. $E$ às vezes, a gente vê que ali tem criança só a aparência sofrida, crianças às vezes desnutrida e você saber que aquela criança ainda não foi destituída porque eles estão tentando colocar de novo no vínculo familiar pra depois, se não der certo, destituir. Aí você saber que as vezes tem dez famílias querendo, tem vinte crianças lá e muitas das vezes a criança passando por esse processo e 
acaba tardando mais ainda a adoção. $E$ eu achei isso aí muito burocrático nessa questão das crianças né, enfim. (Adriana, mãe)

No último momento de entrevista, o casal homoafetivo expressou seus pensamentos e sentimentos vivenciados no decorrer do processo de adoção, considerando o mesmo como benéfico para ambas as partes. No entanto, ao contrário de primeiro momento de entrevista, não cogitavam mais ter 0 segundo filho por receios, de acordo com 0 casal, com o contexto social conturbado em que a sociedade mundial estava vivenciando. Ainda, o casal relatou que a adoção foi uma opção de filiação frente a outras formas. Assim, de acordo com Adriana,

Pra gente que adota, não só pelo fato de eu ter sido um caso . . . por eu ser homoafetiva, eu poderia engravidar né, não foi o fato de eu não pode engravidar que me fez querer adotar, até mesmo porque minha prioridade sempre foi primeiro adotar e depois engravidar se fosse o caso. Mas eu acho que é uma coisa maravilhosa, é uma dádiva de Deus, a gente aprende muito em ver igual 0 Arthur que não tem sangue mas tem os nossos jeitos, nossos gostos, nossos . . . vai muito além né, a gente vê que realmente um laço de amor vai muito além de um laço de sangue e de muitas coisas, né. (Adriana, mãe)

Especificamente com relação à vivência de estigmas por serem um casal homoafetivo, ambas relataram que apesar de não terem vivenciado abertamente, pensavam no assunto. Apontaram que acreditavam que ambientes, como a escola, poderiam introduzir a experiência de discriminação. No entanto, Aline também apontou como um potencial fator protetivo contra discriminações 0 fato de ser respeitada na comunidade em que vivia. Segunda ela,

Até que aqui, graças a Deus, eu sou uma pessoa muito respeitada aqui, eu respeito todo mundo, as pessoas me respeitam. Graças a Deus eu não tenho problema nenhum aqui no bairro que eu moro, nem tive em lugar nenhum pela minha condição sexual. Mas ele, provavelmente, na escola, né, por ter duas mães vai ser uma coisa diferente pras outras crianças, né. Pode ser que venha [o preconceito]. Talvez sim, talvez não. (Aline, mãe)

No último momento de entrevista, Adriana relatou que havia vivido algumas situações em que foi questionada sobre os efeitos que um casal homoafetivo teria para o filho. Por exemplo, ela havia sido perguntada sobre 0 potencial risco de "confundir a cabeça" do filho por ter duas mães, respondendo que até o momento não havia confundido e que 0 filho tratava com naturalidade.

\section{Crenças e Práticas Parentais}

Durante as entrevistas, ambas as famílias destacaram a importância do respeito pelas pessoas, da polidez (dizer bom dia, obrigado, etc.), da assimilação de regras de convivência, e do desenvolvimento da tolerância à frustração. Enquanto a família heteroafetiva destacou o ensino de boas maneiras e obediência, a família homoafetiva enfatizou o diálogo. Essa diferença de estratégias pode ser vista na forma como as famílias lidavam com os comportamentos de "pirraça" dos filhos, com o casal heteroafetivo destacando os castigos e as palmadas e 0 casal homoafetivo a conversa. Ainda, enquanto 0 casal heteroafetivo atribuiu a ocorrência das "pirraças" a uma aprendizagem decorrente do ambiente da creche, 0 casal homoafetivo considerava tais comportamentos como normativos à fase de desenvolvimento infantil de seu filho. Isso pode ser visto nas falas a seguir, 
A Bárbara tá na fase da pirraça, né, não sei onde ela aprendeu, possivelmente deve ter sido na creche com as outras crianças. Ela tá gritando em casa. Se briga com ela, fala que ela não pode fazer isso ou aquilo, ela grita. Então particularmente eu acho que eu sou um pouco mais rígido, então coloco de castigo, dou uma palmada, né, não deixo. Quero que saiba respeitar as pessoas, né. Nós, como pais, e as pessoas mais velhas também. As pessoas em geral. Criação do século XX ainda. (Bernardo, pai)

Já a mãe na familia homoafetiva afirmou,

Ele tá começando essa fase de pirraça. Inclusive, a gente andou lendo algumas coisas, de como reagir, de psicólogo, a gente lê né, pra ver como a gente reage com isso. Porque ele tá entrando na fase de pirraça, então, a gente põe o limite porque não pode deixar, né. Então tá difícil né, porque essa parte de pirraça é algo que é complicado. Que eles fazem mesmo. Mas a gente tenta fazer da melhor forma possível, porque botar de castigo não entende, bater eu não tenho essa teoria de bater. Eu apanhei e nem por isso eu me tornei uma pessoa melhor porque eu apanhei. Eu não acredito nessa teoria. Então, eu acredito que a melhor forma é conversar primeiramente, se não tiver resultado, castigo. (Aline, mãe)

No último momento de entrevista, observamos a manutenção dos discursos de práticas disciplinares rígidas e valorização da obediência e da polidez por parte da família heteroafetiva. $O$ pai era quem assumia as práticas educativas rígidas em relação aos filhos, na crença de que tais práticas eram responsáveis pela educação adequada das crianças a fim de que se tornassem futuros cidadãos que respeitam os outros. Segundo Bernardo, sobre como contribui para 0 desenvolvimento dos filhos,

Acredito que seja em relação a rigidez que eu tenho com eles em alguns momentos, se desobedece, se grita, se faz o que não deve, se exige as coisas ao invés de pedir por favor. Eu já os ensinei a usar a palavrinha mágica que é "por favor" e às vezes eles têm que falar "obrigado," aí eu pergunto "qual é a palavrinha mágica?" e eles falam "por favor," aí eu falo "não, quando você recebe alguma coisa é obrigado." Então eles já estão aprendendo isso. Tô tentando construir . . . educar né, cidadãos. Eu tenho esse . . . até mesmo por ser professor né, eu tenho esse cuidado com as crianças. Quero trazer ideias que venham beneficiar, educar, fazer com que seja uma pessoa que respeite as outras pessoas, eu tento fazer isso. (Bernardo, pai)

Além disso, percebemos que o casal homoafetivo destacou 0 consenso entre 0 casal como importantes para as interações diárias e o casal heteroafetivo discordavam em algumas questões com relação a criação dos filhos. Por exemplo, o casal homoafetivo acreditava ser necessário em uma família que não houvesse desautorização de uma regra estabelecida por uma das mães na frente da criança. De acordo com a Adriana,

A gente tem um comum acordo né, de nenhuma ... acho que é um dos pontos positivos, que a gente conseguiu entrar em comum acordo de que se é não, é não. Não importa a opinião da outra naquele momento, pelo menos não na frente dele [do filho], a gente tem muito disso, ah, eu falar que "não" e ela na frente dele falar que "sim," ai tira uma a autoridade da outra. A 
gente não, se eu falei que "não," ela pode até tá pensando que "sim," mas "não," é "não." (Adriana, mãe)

Já o casal heteroafetivo relatou que a dinâmica familiar envolvia diferentes papéis entre o pai e a mãe, tendo o pai o papel mais rígido e disciplinador, apesar de haver discordância entre os dois. Isso pode ser visto nas seguintes falas,

São várias situações [de interação], tem casos em que eles estão muito desobedientes com a mãe aí eu intervenho porque eu sou mais rígido. Eles sabem que se eu falar alto com eles, se for pra cima alguma coisa vai acontecer né. Essa alguma coisa geralmente é uns tapinhas mesmo. (Bernardo, pai)

Segundo a mãe,

$E u$, às vezes, eu não concordo com ele [o marido] em um quesito, quando ele tá educando, porque ele é rígido, ele é bem mais rígido do que eu pra educar, no sentido de ... é, chamar atenção quando a criança tá fazendo alguma coisa errada, educar né, corrigir, educar não, corrigir. . . . Ele [o marido] acha que tem que ser "não" até o fim. Eu falo "não," mas . . . às vezes, não. Ele [0 filho] tá argumentando comigo, ele tá me explicando, né. . . Para mim o "não" não deve prevalecer em cima do "sim." $E$, às vezes, ele [o marido] não concorda com isso, ele acha que tem que ser "não, não" pro resto da vida. (Bianca, mãe)

Além dessas crenças e práticas parentais sobre a educação dos filhos no geral, também podemos pensar sobre alguns aspectos mais específicos, como a socialização quanto ao fato de os filhos serem adotivos e ao gênero. A seguir destacamos como as famílias lidavam com essas questões.

\section{A Socialização Parental sobre Adoção}

Condizente com as crenças e práticas de educação pautadas no diálogo mencionadas acima, o casal homoafetivo, no primeiro momento de entrevista, afirmou que para abordar a questão da adoção contava histórias para o filho. Segundo Adriana,

A gente conta historinha. A gente conta historinhas biblicas que a gente fala. Igual tem a história de Moisés que foi criado por uma outra família. Às vezes a gente conta história de bichinho que a gente cuida, que não é filho, mas a gente cuida. A gente vai pegando historinhas e vai contando assim. Eu mais porque eu fico maior tempo com ele, eu leio, mostro os livrinhos pra ele, conto historinhas, assim, né. Agora falar assim ainda não teve como, né. Mas a gente conta histórias em relação à adoção pra ele. (Adriana, mãe)

No último momento de entrevista, o casal reiterou as práticas educativas ligadas ao diálogo, como explicar à criança suas curiosidades e conversar abertamente sobre a adoção, independentemente de 0 filho ainda ser pequeno. Adriana defendia que era preciso "jogar limpo" com o filho e não esconder detalhes sobre sua adoção mesmo em tenra idade, pois, de acordo com ela, isso estabeleceria uma relação de confiança com seu filho. Segundo ela,

Ah, eu acho que uma das coisas que eu sou um pouco até mais do que ela [Aline] e que eu sempre falei com ela que eu acho importante é de jogar sempre muito limpo com ele. Tem coisas que igual ela fala comigo que "não tem necessidade de você falar isso com ele ainda, ele ainda só tem dois anos, três anos," e eu gosto de ser muito clara. Se ele me pergunta 
uma coisa, eu não vou desenhar uma história pra hoje ... pra daqui algum tempo ter que contar outra história pra ele, e eu acho que foi um dos pontos que criou uma certa relação positiva, né, dele confiar e saber que realmente eu falei aquilo e é aquilo e que até hoje não mudou. (Adriana, mãe)

Já o casal heteroafetivo, no primeiro momento da entrevista, ainda estava planejando uma conversa sobre adoção, uma vez que os filhos ainda eram pequenos e, segundo o pai, "não tem idade pra saber disso" (Bernardo). No entanto, no último momento da entrevista, o pai relatou que havia começado a contar histórias que envolviam adoção, mesmo que indiretamente, uma estratégia também utilizada pela família homoafetiva. Segundo Bernardo,

Eu já criei uma historinha, sempre que eu tenho um tempo eu sento e chamo "vamos, contar uma história!" . . . "tem a história da corujinha que já tinha um monte de filhinhos e aí teve outro filho," então, vou contando a história né, pra aguçar essa percepção da adoção pra aceitar, pra entenderem isso mais fácil. Acredito que as historinhas que eu conto vai facilitar no dia ... (Bernardo, pai)

\section{A Socialização Parental sobre Gênero}

Com relação a socialização de gênero, as famílias enfatizaram aspectos divergentes. $\mathrm{Na}$ família heteroafetiva, observamos uma manutenção da heteronormatividade, tendo os pais destacado valorizar o ensino das diferenças dos papéis de gêneros, - o qual, segundo 0 pai, deveria ser de responsabilidade da família e não da escola, sendo contrário a uma "ideologia de gênero," nas palavras dele. Isso também foi ressaltado por Bianca,
A minha mãe, ela era professora, né. Eu não tenho essa capacidade de estar alfabetizando, não tenho essa didática pra alfabetizar, mas o que eu posso ensinar, é ensinar as boas maneiras, né. Ensinar ser educado, ensinar a obedecer a tia na escola, ensinar que não pode ficar pelado em qualquer lugar, né, ensinar que ele é menino, que ela é menina, eles já sabem, né. Eles já sabem diferenciar o que é um brinquedo de menina e o que é um brinquedo de menino. Ele fala muito "mãe, eu vou deixar a Bárbara sentar aqui porque eu sou um cavalheiro," "é, você é um cavalheiro meu filho." Entendeu? "Eu vou fazer carinho na minha irmã porque eu sou um cavalheiro," "mãe, eu to brincando de casinha, mas eu sou o papai, tá?" Entendeu a diferença que eles fazem? (Bianca, mãe)

A família homoafetiva, por outro lado, destacou no primeiro momento de entrevista que considerava como um dos seus maiores desafios deixar claro para o filho que ele não precisava seguir a orientação sexual delas. Afirmaram conversar abertamente com 0 filho sobre as diferentes configurações familiares existentes, preparando 0 filho ainda para um potencial preconceito. Segundo Adriana,

Bom, acho que o maior desafio é deixar bem claro pra ele que o que a gente é, ele não é obrigado a ser, né. Assim como meus pais eram heterossexuais, eu não fui, né. Então, não é uma obrigatoriedade. E o que a gente sempre conversa muito e sempre deixar muito claro pra ele assim-que ele tem duas mães, que existe famílias de diversas maneiras, de avós que criam netos, de tios que criam sobrinhos e ele tem duas mães. Então esse é o maior desafio que a gente vê em deixar tudo sempre 
muito claro pra ele, né. E conseguir conquistar ele, convencer ele na questão dele não se importar porque preconceito, assim, todo mundo tem. De alguma maneira, algum momento na vida a gente sofre bullying, a gente sofre... . Mas deixar né, pra ele, que ele respeite também e que ele receba o respeito. (Adriana, mãe)

Ainda, no último momento de entrevista com a família homoafetiva, quando perguntadas sobre como lidava com perguntas relacionadas à orientação sexual, Adriana afirmou,

A gente é tranquilo, a gente responde. A gente entende também que eu acho que existe um tipo de ignorância e de tabu relacionado. Graças a Deus um dos pontos que a gente tem visto muito ultimamente até mesmo por questões políticas "ah porque 0 menino vai ser gay por que é criado por duas mulheres" essas coisas assim nunca perguntaram, nunca questionaram. A gente é adepta à uma criação mais aberta, ah ele quis boneca e a gente deu, isso não tem problema, mas nunca chegaram pra gente e falaram "vocês por serem duas mulheres estão ensinando o menino . . ." nunca questionaram isso pra gente não. (Adriana, mãe)

\section{Discussão e Considerações Finais}

O presente estudo traz contribuições para as pesquisas ao investigar aspectos do processo de adoção e parentalidade ao longo do tempo de duas famílias adotivas, uma heteroafetiva e outra homoafetiva. Destarte, percebemos como o contexto de adoção das duas famílias se configuravam diferentemente, tendo a família heteroafetiva efetuado a primeira adoção "à brasileira" e a segunda dentro dos trâmites legais. Com relação às adoções efetivadas de acordo com a lei, as duas famílias vivenciaram uma espera semelhante por seus filhos. Também de forma semelhante, ambas as famílias teceram críticas a morosidade e burocracia do processo de adoção, o que poderia causar prejuízos às crianças, na opinião dos participantes. Na família homoafetiva, 0 desejo de ter filhos partiu principalmente de uma das cônjuges; isso também foi encontrado no estudo de Tombolato et al. (2019), no qual a iniciativa da adoção partiu de uma das parceiras do casal homoafetivo.

O contexto da homoparentalidade era percebido como trazendo alguns desafios ligados a uma possível vivência de preconceitos, apesar da boa convivência comunitária ter sido trazida como um fator protetivo. Isso está de acordo com o que encontraram Goldberg e Smith (2011) nos Estados Unidos, de que uma maior percepção de apoio social da comunidade estaria ligada a uma maior saúde mental em famílias homoafetivas. Temperini (2018) também encontrou que a maioria dos casais homoafetivos brasileiros e norte americanos participantes de sua pesquisa de doutorado disseram não ter sofrido preconceito, o que atribuíam a comunidade em que viviam. Já Farias (2017) apontou para diversas situações de preconceito vivenciadas pelos casais homoafetivos entrevistados por ela, incluindo situações no local onde moravam (com vizinhos), com profissionais da saúde (médico e plano de saúde), dentre outras. Apesar das mães participantes da presente pesquisa não perceberem ter vivido experiências de discriminação por conta da orientação sexual de forma explícita, acreditavam que isso poderia ocorrer futuramente em ambientes como a escola. Farr (2017) apontou que crianças supostamente estão mais propensas a lidar com discriminação e estigma quando atingem a idade escolar e começam a frequentar outros ambientes como a escola. Isto pode estar relacionado, dentre outras coisas, a uma limitação na formação de profissionais da educação em abordar questões ligadas a diversidade familiar e sexual (Farias, 2016). 
Em geral, condizente com o encontrado por Seidl-de-Moura et al. (2008), os resultados indicaram que ambas as famílias tinham como metas de socialização o bom comportamento. No entanto, observamos um foco diferente entre as famílias ao lidar com vários aspectos da educação dos filhos; enquanto a família heteroafetiva enfatizava práticas disciplinares rígidas com foco na obediência e em seguir regras, a família homoafetiva ressaltava 0 diálogo e a conversa como principais estratégias de socialização. Por exemplo, ambas famílias destacaram os comportamentos de pirraça dos filhos como um desafio, embora tenham diferido na atribuição de causas às esses comportamentos e estratégias para lidar com eles-enquanto a família heteroafetiva apontou para a influência da creche e lidava com o comportamento usando castigos e palmadas, a família homoafetiva atribuiu a pirraça à uma fase normativa do desenvolvimento e buscava a conversa como primeiro recurso.

Também observamos diferenças em relação a outros aspectos da socialização, como a conversa sobre adoção e a educação sobre gênero. Por exemplo, com relação à conversa sobre a adoção, desde o primeiro momento de entrevista na família homoafetiva a mãe buscava introduzir histórias que lidavam indiretamente com 0 assunto da adoção, sendo que no segundo momento enfatizou a importância do diálogo aberto com 0 filho. 0 uso de histórias foi enfatizado na família heteroafetiva apenas no segundo momento de entrevista. Segundo Brodzinsky e Pinderhughes (2002), propiciar um ambiente aberto ao diálogo e favorável as diferenças advindas da adoção, através de uma visão empática da criança $e$ suas origens, é beneficial à adaptação e desenvolvimento da criança adotada.

Ainda, na família homoafetiva, observamos uma socialização de gênero que enfatizava 0 respeito a diversidade e os papéis não definidos socialmente referente ao que seria "de menina" e "de menino." Isso foi o contrário do observado na família heteroafetiva, que buscava ensinar aos filhos os diferentes papéis de gênero. Assim, os dados encontrados aqui estão de acordo com a ideia de que famílias homoafetivas seriam mais flexíveis em seus papéis e priorizam a transmissão de valores ligados a diversidade e liberdade (Araldi \& Serralta, 2019; Cecílio et al., 2013; Farias, 2017; Rosa et al., 2016; Temperini, 2018). Ainda, em consonância com os resultados encontrados nessa pesquisa, os pais entrevistados por Temperini (2018) acreditavam que o diálogo sobre temas como a sexualidade acontecem de forma mais aberta em famílias homoafetivas. Além disso, assim como o casal homoafetivo participante da presente pesquisa, os pais entrevistados por Farias (2017) também apontaram para o diálogo sobre orientação sexual com os filhos e a necessidade de reafirmar aos filhos que a orientação sexual destes não está necessariamente ligado à orientação sexual dos pais. Por outro lado, na família heteroafetiva, observamos uma acentuação dos papéis de gênero, na qual o pai era quem assumia práticas educativas mais rígidas, alinhados com a posição de maior poder por parte do homem, em uma lógica heteronormativa.

Apesar do presente estudo trazer contribuições únicas para literatura ao buscar compreender as interações em famílias com composições diferentes de maneira longitudinal, podemos destacar algumas limitações que devem ser abordadas em estudos futuros. Primeiramente, por ser um estudo de casos, os dados aqui encontrados não podem ser generalizados. Ademais, há de se explorar as consequências de diferentes crenças e práticas parentais para 0 desenvolvimento de crianças em famílias adotivas homoafetivas e heteroafetivas. Há de considerar também a possibilidade de outros fatores estarem ligados às diferenças de crenças e práticas, como histórico familiar, 0 nível socioeconômico da família, e questões raciais; estas são questões promissoras para 
estudos futuros. Por último, no presente estudo, as famílias foram acompanhadas por relativamente pouco tempo. Apesar disso, ressaltamos que 0 uso de métodos qualitativos longitudinais são um avanço nas ciências humanas na contemporaneidade (Hermanowicz, 2016).

Por fim, destacamos a importância de práticas profissionais voltadas às famílias adotivas que visem abordar os benefícios de crenças e práticas parentais com foco na expressão de afeto e limites com base no diálogo (ligados ao estilo parental autoritativo) para o desenvolvimento e crescimento psicológico saudáveis. Ressaltamos que não são as configurações familiares em si que promovem interações e desenvolvimento saudáveis, mas as práticas e interações diárias que ocorrem no âmbito familiar (Farr, 2017; Farr \& Patterson, 2013; Golombok et al., 2014; Reppold, 2001).

\section{REFERÊNCIAS}

Araldi, M. O., \& Serralta, F. B. (2019). O processo de construção e a experiência da parentalidade em casais homossexuais. Psicologia: Teoria e Pesquisa, 35(spe). https://doi.org/10.1590/0102.3772e35n spe1

Araújo, L. F., Oliveira, J. S. C., Sousa, V. C., \& Castanha, A. R. (2007). Adoção de crianças por casais homoafetivos: Um estudo comparativo entre universitários de direito e de psicologia. Psicologia e Sociedade, $\quad$ 19(2), 95-102. https://doi.org/10.1590/S010271822007000200013

Bardin, L. (2004). Análise de conteúdo. (L. A. Reto \& A. Pinheiro, Trads.). Lisboa, Portugal: Edições 70.

Brodzinsky, D. M., \& Pinderhughes, E. (2002). Parenting and child development in adoptive families. Em M. $\mathrm{H}$. Bornstein (Ed.), Handbook of Parenting: Children and Parenting (pp. 279-311). Mahwah, NJ, US: Lawrence Erlbaum Associates Publishers.
Cecílio, M. S., Scorsolini-Comin, F., \& Santos, M. A. (2013). Produção científica sobre adoção por casais homossexuais no contexto brasileiro. Estudos de Psicologia (Natal), 18(3), 507-516. https://doi.org/10.1590/S1413294X2013000300011

Coitinho Filho, R. (2017). Sob o "melhor interesse"! o 'homoafetivo' e a criança nos processos de adoção. Revista Estudos Feministas, 25(2), 495-518. https://doi.org/10.1590/18069584.2017v25n2p495

Conselho Nacional de Saúde (2016). Resolução No 510/2016, de 07 de Abril de 2016. Ministério da Saúde. Diário Oficial [da] República Federativa do Brasil. Brasília, DF. http://conselho.saude.gov.br/resolucoe s/2016/Res0510GM.pdf

Farias, M. O. (2016). Famílias homoparentais e escola: Reflexões e possibilidades. Revista IberoAmericana de Estudos em Educação, 10(6), $\quad$ 1477-1488. https://doi.org/10.21723/riaee.v10i6.833 2

Farias, M. O. (2017). Experiências e vivências de familias homoafetivas com filhos: Vozes de pais, mães e filhos. [Tese de doutorado, Pontifícia Universidade Católica de São Paulo]. Sistema de Publicação Eletrônica de Teses e Dissertações. https://tede2.pucsp.br/handle/handle/20 $\underline{512}$

Farr, R. (2017). Does parental sexual orientation matter? A longitudinal followup of adoptive families with school-age children. Developmental Psychology, 53(2), 252-252. https://doi.org/10.1037/dev0000228

Farr, R., \& Patterson, C. (2013). Coparenting among lesbian, gay, and heterosexual couples: Associations with adopted children's outcomes. Child Development, 84(4), 1226-1240. https://doi.org/10.1111/cdev.12046

Goldberg, A., \& Smith, J. (2011). Stigma, social context, and mental health: 
Lesbian and gay couples across the transition to adoptive parenthood. Journal of Counseling Psychology, 58(1), 139-139. https://doi.org/10.1037/a0021684

Golombok, S., Mellish, L., Jennings, S., Casey, P., Tasker, F., \& Lamb, M. (2014). Adoptive gay father families: Parent-child relationships and children's psychological adjustment. Child Development, 85(2), 456-456. https://doi.org/10.1111/cdev.12155

Harkness, S., Super, C. M., Bermúdez, M. R., Moscardino, U., Rha, J.-H., Mavridis, C. J., ... Zylics, P. O. (2010). Parental ethnotheories of children's learning. Em D.F. Lancy, J. Bock, \& S. Gaskins (Eds.), The anthropology of learning in childhood. Plymouth, United Kingdom: AltaMira Press.

Hermanowicz, J. (2016). Longitudinal qualitative research. In M. J. Shanahan, J. T. Mortimer, \& M. Kirkpatrick Johnson (Eds), Handbook of the life course, Handbooks of Sociology and Social Research (pp. 491-513). Springer, Cham. https://doi.org/10.1007/978-3319-20880-0_22

Kağıtçıbaşı, C. (2007). Family, self, and human development across cultures: Theory and applications (2nd Ed.). Mahwah, NJ: Erlbaum.

Keller, H. (2007). Relations among the dimensions of the parenting model. Em $\mathrm{H}$. Keller (Ed.), Cultures of infancy (pp. 218-226). Mahwah, N.J: Lawrence Erlbaum Associates.

Presidência da República do Brasil (1990) Lei n. 8.069, de 13 de Julho de 1990. Dispõe sobre o Estatuto da Criança e do Adolescente e dá outras providências. Brasília,

DF. http://www.planalto.gov.br/ccivil_03/leis/ 8069.htm

Merçon-Vargas, E. A., Rosa, E. M., \& Dell'Aglio, D. D. (2015). A produção científica e os aspectos legais no âmbito da adoção nacional e internacional. Em F. Scorsolini-Comin, A. Kotzian Pereira, A., M. L. Tiellet Nunes (Eds.) Adoção: legislação, cenários e práticas (pp. 2947). São Paulo: Vetor.

Palacios, J., \& Brodzinsky, D. (2010). Adoption research: Trends, topics, outcomes. International Journal of Behavioral Development, 34(3), 270284.

https://doi.org/10.1177/0165025410362 837

Pereira, C., Torres, A., Falcão, L., \& Pereira, A. (2013). O papel de representações sociais sobre a natureza da homossexualidade na oposição ao casamento civil e à adoção por famílias homoafetivas. Psicologia: Teoria e Pesquisa, 29(1), 79-89. https://doi.org/10.1590/S0102$\underline{37722013000100010}$

Reppold, C. T. (2001). Estilo parental percebido e adaptação psicológica de adolescentes adotados. [Dissertação de mestrado, Universidade Federal do Rio Grande do Sul] https://www.lume.ufrgs.br/bitstream/han dle/10183/3559/000339902.pdf?seque nce=1\&isAllowed=y

Rosa, J. M., Melo, A. K., Boris, G. D. J. B., \& Santos, M. A. (2016). A construção dos papéis parentais em casais homoafetivos adotantes. Psicologia: Ciência e Profissão, 36(1), 210-223. https://doi.org/10.1590/19823703001132014

Ruiz, J. M., Borges, C. A. P., Hueb, M. F. D., Tilio, R., \& Scorsolini-Comin, F. (2019). Gender and adoption in the Brazilian context: An integrative review of the scientific literature. Trends in Psychology, 27(2), 293-308. https://doi.org/10.9788/tp2019.2-01

Seidl-de-Moura, M. L., Lordelo, E., Vieira, M. L., Piccinnini, C. A., Siqueira, J. E O., Magalhães, C. M. C., ... Rimoli, A. (2008). Brazilian mothers' socialization goals: Intracultural differences in seven cities. International Journal of Behavioral Development, 32, 465-472. https://doi.org/10.1177/0165025408093 $\underline{666}$ 
Temperini, C. A. T. (2018). Famílias camaleão: Adaptações, mudanças e desafios da homoparentalidade. [Tese de doutorado, Pontifícia Universidade Católica de São Paulo]. Sistema de Publicação Eletrônica de Teses e Dissertações.

https://tede2.pucsp.br/handle/handle/20 $\underline{976}$

Tombolato, M. A., Maia, A. C. B., \& Santos, M. A. (2019). A trajetória de adoção de uma criança por um casal de lésbicas. Psicologia: Teoria e Pesquisa, 35. https://doi.org/10.1590/0102.3772e354 $\underline{6}$
Tudge, J. R. H. (2008). The everyday lives of young children: Culture, class, and child rearing in diverse societies. New York, NY: Cambridge University Press.

Yin, R. K. (2010). Estudo de caso: Planejamento e métodos. Tradução Ana Thorell. São Paulo, Bookman.

Todos los trabajos publicados en Revista Salud \& Sociedad (ISSNe:0718-7475) están sujetos a una licencia Creative Commons Reconocimiento 4.0 Internacional

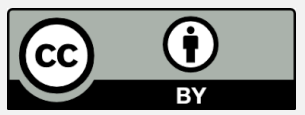

\section{RESUMO}

ANTECEDENTES: A homoparentalidade tem sido foco de estudos recentes, evidenciando a importância de se compreender a dinâmica dessas famílias em comparação às heteroparentais. OBJETIV0: Assim, este estudo buscou compreender as crenças e práticas parentais de uma família adotiva heteroafetiva e outra homoafetiva com filhos pequenos (até três anos de idade). MÉTOD0: Sete entrevistas foram conduzidas com os pais/mães em dois momentos com intervalo aproximado de um ano e oito meses. Para análise de dados utilizamos análise de conteúdo. RESULTADOS: Os resultados mostraram práticas parentais pautadas no diálogo na família homoafetiva e na obediência na família heteroafetiva, bem como as diferentes formas de lidar com questões de gênero. CONCLUSÃO: Ressaltamos que são as crenças refletidas nas práticas diárias que promovem o desenvolvimento e crescimento psicológico saudáveis.

PALAVRAS-CHAVE: Adoção, Famílias adotivas, Famílias homoafetivas, Parentalidade.

\section{RESUMEN}

ANTEDECENTES: La homoparentalidad ha sido el foco de estudios recientes, mostrando la importancia de comprender la dinámica de estas familias en comparación con las heteroparentales. OBJETIVOS: Este estudio buscó comprender las creencias y las prácticas parentales de una familia adoptiva heteroafectiva y una familia adoptiva homoafectiva con niños pequeños (hasta tres años). MÉTODO: Realizamos siete entrevistas con los padres/madres en dos ocasiones con un intérvalo aproximado de un año y ocho meses. Para el análisis de datos usamos análisis de contenido. RESULTADOS: Los resultados mostraron prácticas parentales basadas en el diálogo en la familia homoafectiva y la obediencia en la familia heteroafectiva, así como las diferentes formas de abordar los problemas de género. CONCLUSIONES: Enfatizamos que son las creencias reflejadas en las prácticas diarias las que promueven el desarrollo y el crecimiento psicológicos saludables.

PALABRAS CLAVE: Adopción, Familias adoptivas, Familias homoafectivas, Par entalidad. 